\title{
Development of Life Span Forecasting Model for KHS DMG-VF84 Bottling Line System
}

\section{1'EKEOMA, CG; ${ }^{2}$ ARIRIGUZO, JC; ${ }^{3 *}$ NWADINOBI, CP; ${ }^{2}$ NWANKWOJIKE, BN}

\author{
${ }^{I}$ Department of Mechanical Engineering, Abia State Polytechnic, Aba, Abia State, Nigeria. \\ ${ }^{2}$ Department of Mechanical Engineering, Michael Okpara University of Agriculture, Umudike, Abia State, Nigeria. \\ ${ }^{3 *}$ Department of Mechanical Engineering, Abia State University, Uturu, Abia State, Nigeria. \\ ${ }^{*}$ Corresponding Author Email: chibundop@gmail.com
}

\begin{abstract}
A quadratic model was developed in this study to predict equipment life span for a preventive maintenance planning of KHS DMG-VF84 bottling line system. This life span forecasting model for KHS DMGVF84 bottling line system predict equipment life span at an instant of time. The six key predictors that were significant in the developed model are: Availability (A), Reliability (R), Mean time to Repair (T), Failure rate (F), Operational time $(\mathrm{O})$ and Mean time before failure (B). The model utilized the polynomial method to predict the end of life of the bottling line system. The test data showed that the mean absolute percentage error for this model is $7.5 \%$ and has the ability to predict life span of the bottling line system with a good degree of accuracy of $79.65 \%$ with $\pm 0.20 \%$ error and the coefficients of determination $\mathrm{R}^{2}$ for the developed model is 0.7965 . This indicates that the relationship between the dependent variable and the independent variables of the developed model is good and the predicted values from a forecast model fit with the real-life data as well. Therefore, maintenance professionals should adopt this model for accurate estimates, to enable good detection of possible failures in production machineries.
\end{abstract}

\section{DOI: https://dx.doi.org/10.4314/jasem.v24i5.21}

Copyright: Copyright $($ C 2020 Ekeoma et al. This is an open access article distributed under the Creative Commons Attribution License (CCL), which permits unrestricted use, distribution, and reproduction in any medium, provided the original work is properly cited.

Dates: Received: 15 March 2020; Revised: 25 April 2020; Accepted: 17 May 2020

Keywords: regression model, Time to failure, preventive maintenance planning, bottling line, Availability

A well-designed processing plant is not successful until it is operating safely and profitably. This requires a smooth start-up as well as a productive and safe environment for the operations. In order to sustain the operation, good maintenance practices are required (Oberschmidt et al. 2010, Al- Turky 2011). Troubleshooting is invariably required to detect and fix issues that occur when the performance of engineered equipment degrades (Rommert et al, 2007; Ladi et al, 2007). Due to an increasing complexity of modern production systems, maintenance planning has become more and more important (Denkenaa et al; 2012). This is as companies are generally aiming at more reliable production systems with higher availability performance (Tsu-Ming and Jia-Jeng, 2011). Reliability and maintainability play a crucial role in ensuring the successful operation of plant processes as they determine plant availability and thus contribute significantly to process economics and safety. In addition, maintenance and maintenance policy play a major role in achieving systems' operational effectiveness at minimum cost (Ruiz et al., 2007). In industrial systems, system maintenance is an important factor to retain high utilization of the equipment along with low levels of product failure.
However, if equipment maintenance is not implemented on time, this might result in product failure and seriously affect the production and maintenance plans. For this reason, effectively predicting the equipment preventive maintenance time-point is important (Al-Turky, 2011). Equipment maintenance is classified into two types as corrective maintenance and preventive maintenance (Dhillon, 2002; Márquez, 2007; Tsu-Ming and Jia-Jeng, 2011). In corrective maintenance, repairs are undertaken when equipment fails, restoring it to normal function. For the preventive maintenance, maintenance or replacement occurs during normal functioning of the equipment, which can restore it to a better functioning condition and reduce the probability of equipment failure. This makes for a sustained process. Preventive maintenance is a planned maintenance method developed in order to minimize all the operating machines and equipment breakdowns in an industry to the least extent (Korkut et al., 2009). Hence, carrying out an effective maintenance operation requires efficient planning of maintenance activities and resources. Since planning is performed in order to prepare for future maintenance tasks, it must be based on good estimates of the future maintenance 
requirement. Estimates of the future maintenance requirement are obtained by forecasting, which can be simply defined as predicting the future. Clearly, good forecasts of the maintenance requirement are needed in order to plan well for maintenance resources (Medjaher et al, 2012). In terms of the time horizon, forecasts are typically classified as short-term which ranges from days to weeks; intermediate-term which ranges from weeks to months, and long-term which ranges from months to years. Forecasting techniques are generally classified as qualitative and quantitative. Qualitative (subjective) techniques are naturally used in the absence of historical data (e.g. for new machines or products), and they are based on personal or expert judgment. On the other hand, quantitative (objective) techniques are used with existing numerical data (e.g. for old machines and products), and they are based on mathematical and statistical methods. Meanwhile, the qualitative forecasting techniques include historical analogy, sales force composites, customer surveys, executive opinions, and the Delphi method. For the quantitative techniques are classified into two types. The first is the growth or time-series models that use only past values of the variable being predicted, and the second type is the predictor-variable models that use data of other (predictor) variables. Following the challenges of unplanned disruption in production process, it has become very necessary to develop an adequate model for forecasting preventive maintenance. This study therefore is aimed at utilizing data-driven approach to predict equipment maintenance time point with a preventive maintenance model. Here, condition monitoring data from equipment are extensively analyzed. This is meant to inform on the current status of equipment's health which is important to understand the capability of the equipment to perform its operation for the next cycle of production or ready for maintenance. Hence, this paper presented research on predicting equipment life span for preventive maintenance planning of KHS DMG-VF84 bottling line system. This predicts the future time points for preventive maintenance of the equipment, so that the resource plan at the time points can be well-managed and production will not be significantly disrupted.

\section{MATERIALS AND METHODS}

A biannual breakdown data of the bottling line system which was first made available as primary data were collected and recorded by the Seven-Up Bottling Company (SBC), Aba. The secondary data were collected from the maintenance department of the seven-up bottling company for the purpose of modeling preventive maintenance planning for bottling line system. The lost hour was recorded and was used to calculate for the values of expected run time, operational time, number of failures, meantime time between failure, failure rate, mean time to repair, availability and reliability from 2006 to 2018. The research methodology is based on statistical analysis, which in this work includes the multiple regression analysis. This type of analysis is used for modeling and analyzing several variables. The multiple regression analysis extends regression analysis by describing the relationship between a dependent variable and several independent variables. In this study the dependent variable is the Life span (L) of the bottling line system, while the independent predictor variables are: Availability (A), Reliability (R), Mean time to Repair (T), Failure rate (F), Operational time (O) and Mean time before failure (B). All of these data variables were recorded from 2006 to 2018.

Evaluation procedure and model development: Regression analysis is the process of constructing a mathematical model or function that can be used to predict or determine one variable by another variable or other variables. The variable to be predicted is called the dependent variable and the predictor(s) is/are called the independent variable(s).

The equation of the probabilistic multiple regression model is given in equation (1) as:

$$
y=\beta_{0}+\beta_{1} x_{1}+\beta_{2} x_{2}+\beta_{3} x_{3}+\cdots+\beta_{k} x_{k}+\epsilon
$$

Where: $y=$ the value of the dependent variable; $\beta_{0}=$ the regression constant; $\beta_{1}=$ the partial regression coefficient for independent variable $1 ; \beta_{2}=$ the partial regression coefficient for independent variable $2 ; \beta_{3}=$ the partial regression coefficient for independent variable $3 ; \beta_{k}=$ the partial regression coefficient for independent variable $3 ; k=$ the number of independent variables

Here, $y$ which is equipment Life $\operatorname{span}(L)$ is the response variable, $\beta_{1}, \beta_{2}, \beta_{3, \ldots \ldots . . .} \beta_{n}$ : is the Constants, and $x_{1}, x_{2}, x_{3, \ldots \ldots . . .} x_{n}$ : Represent the independent predictor variables.

To develop the model of multiple regression analysis, equipment Life span $(L)$ values is considered as dependent variable while lost hour, expected run time, operational time, number of failures, meantime time between failure, failure rate, mean time to repair, availability and reliability of the bottling line are the independent variables. In this work, multiple regression analysis is carried out using the MINITAB 17 data analysis in other to derive the relationship. 
To test the validity of the second order model, the following hypotheses were also specified $H_{1}$ : At least one $\beta_{i}$ is not equal to 0.

If the null hypothesis is true, none of the independent variables $x_{1}, x_{2}, \ldots, x_{k}$ is linearly related to $L$, and therefore the model is invalid. If at least one $\beta_{i}$ is not equal to 0 , the model does have some validity. The rejection region is allowed to determine whether $F$ is Large enough to justify rejecting the null hypothesis.

\section{RESULTS AND DISCUSSION}

Modeling the preventive maintenance planning for a bottling line system requires the application of regression analysis in describing the relationship between the equipment Life span (dependent variables) of the bottling line and its performance metrics (independent variables). The independent performance metrics used to determine the response variables of the developed second order model of the bottling line system are the Reliability $(R)$, Failure Rate $(F)$, Mean time to Repair $(T)$, Availability $(A)$, Operational time $(T)$ and Mean Time Before Failure (B) of the bottling line system. Therefore, the developed second order model that relates $(L)$ to different performance metrics of the bottling line system is given in equation (2) as;

$L=74.1-0.0262 R-14.0 F+0.02749 T+0.342 A+$ $0.48901 .410 B+0.000002 R^{2}+0.03 F^{2}+0.00503 R F$

Table 1: Lifetime Regression model Coefficients results

\begin{tabular}{lllll}
\hline Term & Coef & SE Coef & T-value & P-value \\
\hline Constant & $\mathbf{7 4 . 1}$ & $\mathbf{2 9 . 8}$ & $\mathbf{2 . 4 9}$ & $\mathbf{0 . 0 2 5}$ \\
$\mathrm{R}$ & -0.026 & 0.0197 & -1.33 & 0.203 \\
$\mathrm{~F}$ & -14.0 & 11.5 & -1.22 & 0.242 \\
$\mathrm{~T}$ & 0.027 & 0.00807 & 3.41 & 0.004 \\
$\mathrm{~A}$ & 0.342 & 0.301 & 1.13 & 0.275 \\
$\mathrm{O}$ & 0.489 & 0.281 & 1.74 & 0.102 \\
$\mathrm{~B}$ & -1.41 & 0.414 & -3.41 & 0.004 \\
$\mathrm{R}^{2}$ & 0.000002 & 0.000004 & 0.53 & 0.601 \\
$\mathrm{~F}^{2}$ & 0.03 & 1.45 & 0.02 & 0.986 \\
$\mathrm{RF}$ & 0.0050 & 0.00484 & 1.04 & 0.315 \\
\hline
\end{tabular}

Table 2: Analysis of Variance for Lifetime prediction model

\begin{tabular}{|c|c|c|c|c|c|}
\hline Source & DF & Adj SS & Adj MS & $\begin{array}{l}\text { F- } \\
\text { Value }\end{array}$ & $\begin{array}{l}\text { P- } \\
\text { Value }\end{array}$ \\
\hline Regression & 9 & 1601.60 & 177.956 & 6.53 & 0.001 \\
\hline $\mathrm{R}$ & 1 & 48.27 & 48.267 & 1.77 & 0.203 \\
\hline $\mathrm{F}$ & 1 & 40.45 & 40.449 & 1.48 & 0.242 \\
\hline $\mathrm{T}$ & 1 & 316.6 & 316.65 & 11.6 & 0.004 \\
\hline A & 1 & 35.05 & 35.052 & 1.29 & 0.275 \\
\hline $\mathrm{O}$ & 1 & 82.71 & 82.712 & 3.03 & 0.102 \\
\hline B & 1 & 316.39 & 316.39 & 11.6 & 0.004 \\
\hline $\mathrm{R}^{2}$ & 1 & 7.80 & 7.803 & 0.29 & 0.601 \\
\hline $\mathrm{F}^{2}$ & 1 & 0.01 & 0.008 & 0.00 & 0.986 \\
\hline $\mathrm{RF}$ & 1 & 29.45 & 29.452 & 1.08 & 0.315 \\
\hline Error & 15 & 409.09 & 27.273 & & \\
\hline Total & 24 & 2010.69 & & & \\
\hline
\end{tabular}

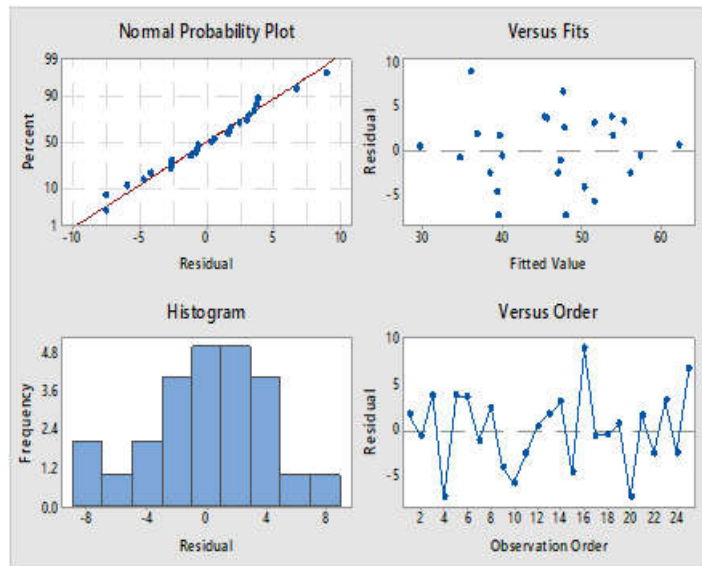

Fig. 1: Residual plots of $L$ for second order model

Table 1 is the regression analysis MINITAB output for equipment Life span (L) versus reliability, failure rate, mean time to repair, availability, operational time and mean time before failure. It was observed that the value of the coefficient of determination $\left(R^{2}\right)$ is $79.65 \%$, which means that the model fits the data well and can be used to predict L at $79.65 \%$ with $\pm 0.20 \%$ error. The value of the $F$ statistic is 6.53 which has a $p$-value of 0.001 , this confirms that the model is valid. Table 2 shows that the statistic value of $F=6.53$ is greater than the critical value of $F_{0.05,9,15}=2.59$, hence the model is valid. The models adequacy for the $\mathrm{L}$ is further confirmed using the residual plots which comprises of the; normal probability plot, histogram, residual versus fitted values and residual versus observation. Fig. 1 showed that the residual data points are evenly distributed. Also the histogram plot indicated that the highest error frequency of approximately 5.2 which showed that the model error deviation is insignificant. Hence, the second order model of the L depicted a zero skew histogram and probability plot which depicted statistical adequacy to fit the data.

Model Confirmatory Test: The results of the model confirmatory test shown in table 3 indicates that the fitted functions are good fits for the Life span (L) responses. Table 3 shows the actual Life span, predicted life span and the percentage error for the second order model. The percentage error ranges from $\sim 0.9$ to $23.5 \%$. Hence, the second order developed multiple regression model is justifiably accurate, because the results of the observations are within $95 \%$ prediction interval, which represents a range that a single new observation is presumed to fall into. Also, the results show that the statistic value of $F=6.53$ is greater than the critical value of $F_{0.05,9,15}=2.59$, hence the model is valid. 


\begin{tabular}{|c|c|c|c|c|c|c|}
\hline S/NO. & $\begin{array}{l}\text { Actual } \\
\text { life span }\end{array}$ & $\begin{array}{l}\text { Predicted } \\
\text { Life span }\end{array}$ & Error & $\begin{array}{l}\text { ABS } \\
\text { (A-P) }\end{array}$ & $\begin{array}{l}\text { ABS (A- } \\
\text { P)/A }\end{array}$ & $\begin{array}{l}\text { Error } \\
\%\end{array}$ \\
\hline 1 & 55.5 & 53.8 & 1.66 & 1.66 & 0.029831733 & 3.0 \\
\hline 2 & 33.8 & 34.6 & -0.80 & 0.80 & 0.023734132 & 2.4 \\
\hline 3 & 49 & 45.1 & 3.8 & 3.8 & 0.077846826 & 7.8 \\
\hline 4 & 31.9 & 39.4 & -7.52 & 7.52 & 0.235821108 & 23.5 \\
\hline 5 & 57.4 & 53.7 & 3.72 & 3.72 & 0.064909541 & 6.5 \\
\hline 6 & 49 & 45.5 & 3.51 & 3.51 & 0.071781802 & 7.2 \\
\hline 7 & 46 & 47.2 & -1.24 & 1.24 & 0.026997391 & 2.7 \\
\hline 8 & 50.2 & 47.7 & 2.45 & 2.45 & 0.048921931 & 4.9 \\
\hline 9 & 46 & 50.2 & -4.16 & 4.16 & 0.090647002 & 9.1 \\
\hline 10 & 45.5 & 51.4 & -5.92 & 5.92 & 0.130182468 & 13.0 \\
\hline 11 & 44.2 & 46.8 & -2.69 & 2.69 & 0.06100321 & 6.1 \\
\hline 12 & 29.8 & 29.5 & 0.33 & 0.33 & 0.011226706 & 1.1 \\
\hline 13 & 38.4 & 36.7 & 1.72 & 1.72 & 0.044872324 & 4.5 \\
\hline 14 & 54.4 & 51.4 & 2.98 & 2.98 & 0.054962928 & 5.5 \\
\hline 15 & 34.5 & 39.2 & -4.72 & 4.72 & 0.136840326 & 13.7 \\
\hline 16 & 44.9 & 36.0 & 8.88 & 8.88 & 0.197855456 & 19.8 \\
\hline 17 & 56.5 & 57.2 & -0.70 & 0.70 & 0.012408526 & 1.2 \\
\hline 18 & 39.3 & 39.9 & -0.64 & 0.64 & 0.016341444 & 1.6 \\
\hline 19 & 62.8 & 62.2 & 0.59 & 0.59 & 0.00954917 & 0.9 \\
\hline 20 & 40.3 & 47.8 & -7.51 & 7.51 & 0.186376483 & 18.6 \\
\hline 21 & 41.1 & 39.5 & 1.56 & 1.56 & 0.038018599 & 3.8 \\
\hline 22 & 35.7 & 38.3 & -2.58 & 2.58 & 0.072364987 & 7.2 \\
\hline 23 & 58.5 & 55.3 & 3.19 & 3.19 & 0.054573342 & 5.5 \\
\hline 24 & 53.5 & 56.0 & -2.58 & 2.58 & 0.048262788 & 4.8 \\
\hline 25 & 54.2 & 47.5 & 6.64 & 6.64 & 0.122539756 & 12.3 \\
\hline
\end{tabular}

Conclusion: In this study, a second order model was developed to predict equipment Life span for a preventive maintenance planning of a bottling line system. The model selected the most suitable variables from the distribution that was used for prediction. It has the ability to predict Life span for bottling line system with a good degree of accuracy. The average accuracy percentage for the model is $92.5 \%$, which shows that the model is reliable in prediction. Hence, maintenance professionals should adopt this model to enable good detection of possible failures in production machineries.

\section{REFERENCES}

Al-Turky U (2011). A framework for strategic planning in maintenance. J Quale. Maintain. Eng. 17(2): 150162.

Denkenaa, B; Kröninga, S; Doreth, K (2012). Operational Planning of Maintenance Measures framework for maintenance performance measurement (MPM). J. Qua. Maint. Eng. 4(1): 611 .

Dhillon, BS (2002). Engineering Maintenance - A Modern Approach. CRC Press, ISBN 1-58716-1427, Boca Raton London New York Washington, D.C. :55-122.

Korkut, SD; Bekar, D; Ertugrul, D (2010). Application of preventive maintenance planning in a parquet enterprise. Afr. J. Biotechnol. 8(1):1-5.

Ladi, O; Sosimi, AA; Shittu, KO; Oyetunji, EO; Oke SA (2007). Maintenance Job Scheduling: A Multi-
Criteria Approach Under Stochastic-Fuzzy Uncertainty. Kmitl sci. Tech. J. 7(2): 3-5.

Márquez, AC (2007). The maintenance management framework: models and methods for complex systems maintenance. Springer-Verlag, London Ltd. 333-334.

Medjaher, K; Tobon-Mejia, DA; Zerhouni, N (2012). Remaining Useful Life Estimation of Critical Components with Application to Bearings. IEEE J. Transact.Reliability. 61(2):292-302.

Oberschmidt, J; Geldermann, J; Ludwig, J; Schmehl, M (2010). Modified PROMETHEE approach for assessing energy technologies. Int J En Sect Manag. 4(2): 183-212.

Rommert, D; Robin, PN; Lodewijk, CMK (2007) Maintenance and Markov Decision Models. Econometric Institute, Erasmus University Rotterdam, PO Box 1738, NL-3000 DR Rotterdam. The Netherlands. 1-16.

Ruiz, R; Garcia, D; Carlos, J; Maroto, C (2007). Considering scheduling and preventive maintenance in the flow-shop sequencing problem. Comp. and OR, 34: 3314-3330.

Tsu-Ming, Y; Jia-Jeng, S (2011). Preventive maintenance model with FMEA and Monte Carlo simulation for the key equipment in semiconductor foundries. Sci. Res. Essays. 6(2): 2-8. 